\title{
PAPEL DAS FORMAS CONSENSUAIS DE RESOLUÇÃO DE CONFLITOS DURANTE A PANDEMIA DO NOVO CORONAVÍRUS (COVID-19)
}

\section{ARTIGO ORIGINAL}

DUARTE, Bianca Cristina Fernandes ${ }^{1}$

LASCIO, Marília Lizia Veloso Santana $\mathrm{Di}^{2}$

DUARTE, Bianca Cristina Fernandes. LASCIO, Marília Lizia Veloso Santana Di. Papel das formas consensuais de resolução de conflitos durante a pandemia do novo coronavírus (Covid-19). Revista Científica Multidisciplinar Núcleo do Conhecimento. Ano 05, Ed. 12, Vol. 15, pp. 173-182. Dezembro de 2020. ISSN: 2448-0959, Link de acesso: https://www.nucleodoconhecimento.com.br/lei/papel-das-formas

\section{RESUMO}

O presente artigo visa explanar modos de resolução de conflitos com os quais o judiciário brasileiro pode se beneficiar para adequação, da maneira mais eficiente e econômica possível, ao cenário pandêmico do novo coronavírus (Covid-19). Ademais, discorre acerca dos papéis da mediação e da conciliação na solução das dificuldades - tangentes à quantidade de processos em andamento - enfrentadas pelo Poder Judiciário no Brasil, tanto durante quanto após a crise que se encontra eminente. Analisa-se ainda a contribuição advinda do Código de Processo Civil de 2015, especificamente em seu artigo $3^{\circ}\left(\S 2^{\circ}\right.$ e $\left.\S 3^{\circ}\right)$, quanto ao incentivo à autocomposição. O trabalho foi desenvolvido segundo uma metodologia exploratória a partir da análise doutrinária, legislativa e de dados do Conselho Nacional de Justiça.

\footnotetext{
1 Graduando em Direito.

2 Graduando em Direito.
} 
Palavras-chave: resolução de conflitos, autocomposição, mediação, conciliação, Covid-19.

\section{INTRODUÇÃO}

Em março de 2020, a Organização Mundial da Saúde (OMS) declarou a elevação do estado de contaminação pelo novo coronavírus ao status de pandemia. Desde então, o cenário pandêmico causa situações completamente sem precedentes no cotidiano global, que frequentemente tem de ser encaradas pelo Judiciário.

A hodierna conjuntura apresenta não apenas uma crise sanitária, como também entre outros - econômica, educacional, jurisdicional. Foca-se nesta última, visto que as litigiosidades se exacerbaram em meio às contingências da realidade. Esse quadro é evidenciado também no Brasil, onde além de problemas decorrentes de uma situação inusitada e abrupta, a cultura do conflito, já existente na sociedade, ficou ainda mais visível.

A fim de que esses conflitos não quebrem o já debilitado sistema judiciário brasileiro, busca-se mostrar aqui, baseado em métodos exploratórios, meios alternativos de acesso à justiça, especificamente a conciliação e a mediação, que aparecem como formas mais adequadas de lidar com determinadas formas de litigiosidade.

\section{SOBRE A CONCILIAÇÃO, A MEDIAÇÃO E AS INOVAÇÕES ADVINDAS DO CÓDIGO DE PROCESSO CIVIL DE 2015}

Para compreender a conciliação e a mediação, faz-se imperioso observar alguns pontos acerca da mitigação de litígios, sem exaustão, para que seja compreendido o cenário no qual se encaixam na doutrina.

As formas de resolução de conflitos apresentam-se divididas em duas categorias no que se refere a quem tem poder decisório: heterocomposição e autocomposição. Naquela tem-se a interferência direta de um terceiro que terá competência para julgar o litígio e impor uma decisão, seja por meio do processo estatal, seja por arbitragem. 
Esta, que é o enfoque de nosso trabalho, revela formas de soluções consensuais de conflitos, trazendo à tona o protagonismo das partes.

De fato, há duas formas de autocomposição, como nos revelam Marioni, Arenhart e Mitiedeiro (2017): "A autocomposição pode ocorrer de forma espontânea (transação, reconhecimento jurídico do pedido e renúncia ao direito) ou de forma estimulada (conciliação e mediação)" (p.140).

Pode-se fazer uma relação análoga entre tais formas de autocomposição estimulada e o modelo de Stuttgart, que foi produzido na Alemanha, na década de 70, por Fritz Bauer e Franz Klein, e é responsável por criticar a imagem inerte do juiz e incentivar a função assistencial deste. Assim, é reconhecido por certos teóricos como o gérmen das formas consensuais de resolução de conflitos na modernidade.

No Brasil, a mediação e a conciliação surgem, mesmo que tardiamente, como alternativas ao sistema judiciário estatal, quando os litígios tratam de direitos disponíveis. Por serem formas de resolução de conflitos que instigam o protagonismo das partes, tendem a obter resultados que agradam os litigantes, diferente do que pode vir a acontecer numa decisão do juiz natural.

Nesse sentido, é importante trazer em questão o pensamento de Lilia Maia de Morais Sales e Cilana de Morais Soares Rabelo (2009):

Os métodos alternativos/consensuais/adequados de resolução de conflitos não foram criados ou aprimorados para substituir o modelo tradicional de utilização do sistema judicial, nem para descongestioná-lo (não havendo, inclusive, qualquer relação de hierarquia entre o Poder Judiciário e os mecanismos consensuais), mas sim para propiciar opções viáveis, alternativas para as pessoas que buscam soluções diferenciadas, específicas, e, talvez, especializadas para suas distintas inter-relações. (p.77)

O instituto da conciliação foi consagrado pelo Código de Processo Civil de 1973 e o da mediação, pela Resolução ㄲ125/2010 do Conselho Nacional de Justiça (CNJ). No entanto, é apenas em 2015 que essas formas passam a ser amplamente incentivadas pelo ordenamento jurídico brasileiro. 
O legislador, com o intuito de aprimorar o arranjo jurisdicional, promulgou a lei $\mathrm{n}^{\circ}$ 13.105/2015, que instituía o então novo Código de Processo Civil (CPC). Apresentase, além de outras mudanças relevantes, o impulso ao uso da mediação e da conciliação, expresso no artigo $3^{\circ}$, parágrafos $2^{\circ}$ e $3^{\circ}$, da referida lei:

Art. $3^{\circ} \ldots$

$\S$ 2o O Estado promoverá, sempre que possível, a solução consensual dos conflitos.

§ 3ำ A conciliação, a mediação e outros métodos de solução consensual de conflitos deverão ser estimulados por juízes, advogados, defensores públicos e membros do Ministério Público, inclusive no curso do processo judicial.

Além de tal artigo, há inúmeros outros que orientam como devem ser conduzidos tais meios de resolução de litígios, desde a exigência de cooperação das partes às atividades desempenhadas pelos conciliadores e mediadores.

O artigo 165 do CPC designa não apenas as diferenças entre conciliadores (sugerem decisões para litigantes que se desconheciam) e mediadores (restabelecem o canal comunicativo entre partes que se conheciam previamente, sem sugerir decisões), importante para solucionar divergências doutrinárias, como também a exigência da criação de centros judiciários de solução consensual de conflitos, devendo os tribunais definir a composição e a organização de cada centro, sob observação às normas do Conselho Nacional de Justiça.

A já citada Resolução nำ125/2010 do CNJ estabeleceu importantes normas de regulamentação das atividades de autocomposição, com vistas a uniformizar o tratamento da mediação e conciliação no Brasil. Além disso, revela quais os benefícios dessas formas alternativas de acesso à justiça.

Entre as considerações expostas pela resolução, destaca-se esta:

que a conciliação e a mediação são instrumentos efetivos de pacificação social, solução e prevenção de litígios, e que a sua apropriada disciplina em programas já implementados no país tem reduzido a excessiva 
judicialização dos conflitos de interesses, a quantidade de recursos e de execução de sentenças. (p.2)

Ademais, como afirma Didier Jr., tais meios de negociação não se restringem a melhorias na eficácia jurisdicional e na diminuição de gastos na economia, pois, ao fazerem das partes interessadas protagonistas, construindo as decisões judiciais coadunadas, também amadurecem e desenvolvem o instrumento social da cidadania.

Por outro ângulo, ainda que seja um instrumento que vigora há certo tempo, as formas consensuais até então não estão bem difundidas, não obstante seu crescimento no sistema processual brasileiro. De acordo com o CNJ, em 2017, 12,1\% dos processos foram resolvidos por meios consensuais, o que em números absolutos equivale a 3,7 milhões de um assustador montante de 31 milhões de sentenças, situação analisada a seguir.

\section{O EXACERBADO NÚMERO DE PROCESSOS EM JULGAMENTO NO PODER JUDICIÁRIO BRASILEIRO}

Historicamente, o trajeto delineado pelo sistema jurídico brasileiro sofre com extrema lentidão e abarrotamento de processos, o que torna o modo jurisdicional dispendioso. Segundo relatório do CNJ, em 2017, as despesas do judiciário já correspondiam a 90,8 bilhões de reais, parte substancial do Produto Interno Bruto (PIB) Nacional.

Em adição a isso, o mesmo relatório afirma que apesar do quadro anterior de grandes gastos, não houve diminuição dos processos que aguardavam julgamento, ainda que a produtividade dos magistrados tenha tido um aumento significativo. Conclui-se, assim, que o crescimento do volume processual é um fato.

A conjuntura do ano de 2020 , até o presente mês de agosto, permeada pela pandemia causada pelo novo coronavírus é fator impulsionar de um aumento súbito e constante dessa quantidade já avassaladora de processos. Se antes da pandemia o cenário possuía grandes falhas e problemáticas, agora a situação tem de ser observada e manuseada de forma ainda mais delicada, a fim de não culminar em total colapso do sistema jurídico brasileiro. 
Deve-se, portanto, fazer uma breve análise dos novos casos que adentraram e continuam adentrando a maquinaria processual judicial, a fim de perceber que poderiam ser solucionados por meio de formas alternativas, mais adequadas aos conflitos em questão.

Em acesso às ações que possuem indicação de COVID-19 nos dados básicos do processo, no dia 28 de agosto de 2020, pelo site do CNJ, encontra-se um total de 94 mil processos. Ao dividir esses processos por classe, revela-se uma situação que corrobora com o pensamento desenvolvido até o momento. A tabela a seguir é montada com os dados do próprio site e mostra as cinco classes mais litigadas:

Figura 01: Ações relativas à Covid-19 no âmbito do CNJ por classe.

\begin{tabular}{|l|l|}
\hline Classe & Quantidade \\
\hline Procedimento do Juizado Especial Cível & 56081 \\
\hline Auxílio Emergencial & 10371 \\
\hline Habeas Corpus Criminal & 9924 \\
\hline Agravo de instrumento & 4780 \\
\hline Mandado de segurança & 4148 \\
\hline
\end{tabular}

Fonte: CNJ, (2020).

Percebe-se que a leitura dos dados indica, além da quantidade elevada de litígios decorrentes da pandemia submetidos ao judiciário, a prevalência de procedimentos nos Juizados Especiais Cíveis (JEC). Esses juizados tratam de casos considerados de menor complexidade pela legislação, geralmente relativos a pequenas causas e direitos disponíveis.

A grande maioria dos processos que chegam aos JEC é, destarte, adequada à dissolução por meio das formas consensuais de resolução de conflitos. Não à toa, esses juizados têm competência para realizar conciliações, como estabelece Lei no 9.099/1995. 
Em razão da natureza da maior quantidade dos procedimentos chegados ao judiciário nesse cenário pandêmico, demonstra-se aqui a relevância que deve ser dada às formas autocompositivas estimuladas no momento presente.

\section{O PAPEL DOS MÉTOdOS DE CONCILIAÇÃO E MEDIAÇÃO DURANTE A PANDEMIA DO COVID-19}

O indispensável e importante papel dos métodos consensuais, sejam judiciais ou extrajudiciais, é claro no cenário atual, uma vez que se apresentam como uma alternativa hábil para a resolução de conflitos frente à pandemia do COVID-19 e propiciam o não colapso da máquina jurisdicional.

Devido aos benefícios já supracitados neste artigo, no dia 24 de Abril de 2020, houve uma alteração na Lei oㅜ 9099/1995, para assim poder possibilitar a conciliação não presencial no âmbito dos Juizados Especiais Cíveis, isto é, de maneira remota, utilizando os meios eletrônicos como ponte para vincular as partes.

Assim, quando contratos e acordos não podem ser cumpridos em consequência do panorama atual, o ideal é que as partes consigam renegociar, sem a interferência de um terceiro. Entretanto, se estas não conseguirem chegar a um consenso sozinhas, haverá duas alternativas: ação judicial ou conciliação e mediação.

Na primeira escolha, defronta-se com um cenário quase inviável: muitos serviços estão paralisados ou com um funcionamento parcial, há suspensão de prazos, e possivelmente, após o quadro hodierno normalizar-se, continuará com as falhas críticas preexistentes ou pioradas.

A segunda alternativa, por sua vez, encontra-se disponível e legalmente ativa pela já citada alteração estabelecida pela Lei 13.994/2020, para funcionar através de meios eletrônicos, tentando adequar-se ao novo quadro de isolamento social.

Duas problemáticas são levantadas quanto às resoluções não presenciais. Primeiro, as dificuldades no acesso de todos de forma isonômica a essas formas de resolução de litígios em meios não presenciais. Fato que se deve a situações graves de 
vulnerabilidade processual que podem ser enfrentadas nos casos concretos, como falta de internet. Além dessa adversidade apresentada, muitos juizados não encontravam em sua rotina o trabalho remoto e, desse modo, ainda utilizam poucos meios eletrônicos e virtuais.

Entretanto, a alteração dessa resolução é capaz de evidenciar uma nova perspectiva para além da situação pandêmica, a qual poderia adiar-se por anos. A sociedade vêse progressivamente digitalizada, enquanto o judiciário não a vinha acompanhando. Assim, a Lei 13.994/2020 inicia a possibilidade de mudar essa realidade fazendo com que computadores, smartphones e outras tecnologias se tornem um meio de acesso à justiça.

Ainda não há jurisprudência formada quanto a situações nas quais uma das partes não dispõe de conhecimento acerca do uso dos meios digitais ou ainda a falhas nos aparelhos de comunicação virtual. No entanto, a Resolução n`322 do CNJ, de 01 de junho de 2020, estabeleceu diretrizes para a volta das atividades nos tribunais a partir de 15 de junho, desde que seguidas devidamente as orientações das autoridades sanitárias. Dessa forma, os CJUS (Centro Judiciário de Resolução de Conflitos) podem disponibilizar aparatos como computadores e internet para as partes que assim necessitarem e solicitarem.

Em adição a isso, a Portaria ${ }^{\circ} 61$ também do $\mathrm{CNJ}$, de 31 de março de 2020, propiciou a disponibilização de uma plataforma emergencial de videoconferência para a realização de audiências e sessões de julgamento nos órgãos do Poder Judiciário. Esta plataforma, a qual se manuseia o aplicativo CiscoWebex, possibilita a uniformização do meio utilizado nas sessões de conciliação dos JEC e CJUS. Ainda assim, os órgãos têm poder de escolha sobre empregar essa ferramenta ou outras, como e-mail e até mesmo WhatsApp.

Importante é, pois, destacar a grande valia da Recomendação CSJT.GVP № 01/2020, de 25 de março de 2020 do Vice-Presidente do Tribunal Superior do Trabalho (TST) e do Conselho Superior da Justiça do Trabalho (CSJT), Ministro Luiz Philippe Vieira de Mello. Nesse documento recomenda-se: 
A adoção de diretrizes excepcionais para o emprego de instrumentos de mediação e conciliação de conflitos individuais e coletivos em fase processual e fase pré-processual por meios eletrônicos e videoconferência no contexto da vigência da pandemia do Novo Coronavírus (COVID-19). (p.1)

Se o meio remoto for impossível, no entanto, os litigantes podem optar por esperar a normalização da situação, caso o litígio não seja urgente, e se utilizar posteriormente das formas consensuais presenciais, que, no geral, não sofrem das falhas críticas apontadas anteriormente.

Apesar de tudo, a busca pela mediação encontra-se crescente em diversos pontos do país, como no Tribunal Regional do Trabalho da $4^{a}$ Região (TRT-RS) que, entre 16 de março e 23 de abril de 2020, apresentou um crescimento de 156\% nas mediações entre empregados e empregadores (inferior ao aumento de $292 \%$ nas audiências).

É cedo para dizer se essa expansão no uso dos meios consensuais é devida ao conhecimento de seus benefícios ou apenas proporcional ao crescimento de lides. Por essa razão, defende-se amplamente os dispositivos do CPC que impõem a cooperação dos profissionais do direito para o incentivo das formas consensuais.

Reduzir a quantidade de processos submetidos aos tribunais e propiciar resoluções de litígios que agradem as partes são objetivos amplamente queridos. Por um lado, a diminuição no número de processos gerará ganhos econômicos necessários neste período de crise. Por outro, os ânimos já aflorados dos indivíduos são poupados de mais indignações com a justiça e o Estado.

\section{CONSIDERAÇÕES FINAIS}

Dado o exposto, é evidente o impacto que a pandemia do ano de 2020, provocada pelo novo coronavírus, pode trazer ao ramo processual, principalmente no que diz respeito aos aumentos significativos na quantidade de processos submetidos ao judiciário. Assim, o papel das formas consensuais de resolução de conflitos ganha uma importância ainda maior, devendo ser incentivada e utilizada de forma ampla, com os devidos cuidados para que a isonomia das partes seja respeitada. Entende- 
se que, sem intenção de fazer previsões exatas, a mediação e a conciliação terão maior enfoque no cenário brasileiro da pandemia em diante, devido aos incentivos propiciados pelo CPC e a maior necessidade desses meios atualmente.

\section{REFERÊNCIAS}

AÇÕES JUDICIAIS - COVID-19. Conselho Nacional de Justiça, 2020. Disponível em:

$<$ https://observatorionacional.cnj.jus.br/observatorionacional/index.php/coronaviruscovid19/acoes-judiciais>. Acesso: 28 de ago. de 2020

\section{BRASIL. Código de Processo Civil, Constituição Federal, Legislação Processual}

Civil. 15. ed. São Paulo: Revista dos Tribunais, 2010.

BRASIL. Lei no 9099, de 26 de setembro de 1995. Dispõe sobre os Juizados Cíveis e Criminais e dá outras providências. Planalto. Disponível em: <http://www.planalto.gov.br/ccivil_03/leis//9099.htm>. Acesso em: 14 jun. 2020.

BRASIL. Lei n¹3.994, de 24 de abril de 2020. Altera a Lei n`9099, de 26 de setembro de 1995, para possibilitar a conciliação não presencial no âmbito dos Juizados Especiais Cíveis. Planalto. Disponível em: <http://www.planalto.gov.br/ccivil_03/_Ato2019-2022/2020/Lei/L13994.htm>. Acesso em: 14 jun. 2020.

BRASIL. Portaria $n^{\circ} 61$, de 31 de março de 2020 . Institui a plataforma emergencial de videoconferência para realização de audiências e sessões de julgamento nos órgãos do Poder Judiciário, no período de isolamento social, decorrente da pandemia Covid19. Conselho Nacional de Justiça. Disponível em: $<$ https://atos.cnj.jus.br/files/original221645202004015e8512cda293a.pdf>. Acesso em: 14 jun. 2020.

BRASIL. Recomendação CSJT.GVP № 01/2020, de 25 de março de 2020. Recomenda a adoção de diretrizes excepcionais para o emprego de instrumentos de mediação e conciliação de conflitos individuais e coletivos em fase processual e fase 
pré-processual por meios eletrônicos e videoconferência no contexto da vigência da pandemia do Novo Coronavírus (COVID-19). Conselho Superior da Justiça do Trabalho. Disponível em: <https://www.conjur.com.br/dl/recomendacao-tstvideoconferencia.pdf>. Acesso em: 14 jun. 2020.

BRASIL. Resolução $n^{\circ} 125$, de 29 de novembro de 2010. Dispõe sobre a Política Judiciária Nacional de tratamento adequado dos conflitos de interesses no âmbito do Poder Judiciário e dá outras providências. Conselho Nacional de Justiça. Disponível em:<https://atos.cnj.jus.br/files/resolucao_comp_125_29112010_19082019150021.p df>. Acesso em: 14 jun. 2020.

BRASIL. Resolução n³22, de 01 de junho de 2020. Estabelece, no âmbito do Poder Judiciário, medidas para retomada dos serviços presenciais, observadas as ações necessárias para prevenção de contágio pelo novo Coronavírus - Covid-19, e dá outras providências. Conselho Nacional de Justiça. Disponível em: $<$ https://atos.cnj.jus.br/files/original155647202006025ed676bf4c0d5.pdf>. Acesso em: 14 jun. 2020.

Conselho Superior Da Justiça Do Trabalho recomenda mediação e conciliação em meio eletrônico durante pandemia. Portal da Indústria: Conexão Trabalho, 2020. Disponível em: $<$ https://conexaotrabalho.portaldaindustria.com.br/noticias/detalhe/trabalhista/geral/conselho-superior-da-justica-do-trabalho-recomenda-mediacao-e-conciliacaoem-meio-eletronico-durante-pandemia/>. Acesso em: 04 de mai. de 2020

DIDIER JR., Fredie. Curso de Direito Processual Civil: teoria geral do processo e processo de conhecimento - vol.1. 19. ed. Salvador: Editora Jus PODIVM, 2017.

LINHA DO TEMPO DO CORONAVÍRUS NO BRASIL. Sanar saúde, 2020. Disponível em: < https://www.sanarmed.com/linha-do-tempo-do-coronavirus-no-brasil>. Acesso em: 11 de jun. de 2020.

MARIONI, Luiz Guilherme; ARENHART, Sérgio Cruz; MITIDIERO, Daniel. Teoria do Processo Civil - vol.1. 3. ed. São Paulo: Editora Revista dos Tribunais, 2017. 
Pandemia reflete em aumento de $156 \%$ no número de casos de mediação trabalhista. Gaúchazh: Economia, 2020.2 Disponível em: <https://gauchazh.clicrbs.com.br/economia/noticia/2020/04/pandemia-reflete-emaumento-de-156-no-numero-de-casos-de-mediacao-trabalhistack9hwdh5700cv017nsf230g7e.html>. Acesso em: 04 de mai. de 2020

SALES, Lilia Maia de Morais; RABELO, Cilana de Morais Soares. Meio consensuais de resolução de conflitos: instrumentos de democracia. Revista de Informação Legislativa, Brasília, a. 46 n. 182 abr.jun. 2009.

Enviado: Junho, 2020.

Aprovado: Dezembro, 2020. 